\title{
Investigation of polymerization of benzoxazines and thermal degradation characteristics of polybenzoxazines via direct pyrolysis mass spectrometry
}

\author{
Shahla Bagheri Fam, ${ }^{a}$ Tamer Uyar, $^{\text {b† }}$ Hatsuo Ishida ${ }^{\mathrm{b}}$ and Jale Hacaloglu ${ }^{\mathrm{a} *}$
}

\begin{abstract}
Polymerization of benzoxazines and thermal degradation mechanisms of polybenzoxazines were investigated using the direct pyrolysis mass spectrometry (DP-MS) technique. The benzoxazine structures were based on phenol and aniline and on bisphenol-A and methylamine or aniline. Polymerizations of the benzoxazines were carried out by curing them at elevated temperatures without addition of initiator or catalyst. DP-MS data showed the presence of chains generated by opposing polymerization reaction pathways indicating quite complex structures for the polybenzoxazines under investigation. Thermal decomposition of polybenzoxazines was started by the cleavage of methylamine or aniline linkages. It was determined that polybenzoxazines based on phenol were more stable than the corresponding bisphenol-A-based polybenzoxazines, while those based on methylamine were more stable than the corresponding polybenzoxazines incorporating aniline. Thus, it can be concluded that the presence of bulky groups decreased the extent of crosslinking which in return decreased the thermal stability.
\end{abstract}

(C) 2012 Society of Chemical Industry

Keywords: benzoxazine; polybenzoxazine; curing; thermal degradation; pyrolysis mass spectrometry

\section{INTRODUCTION}

For advanced composites, polymers with easy processability, good mechanical properties and high thermal stability are in increasing demand as matrix materials. In order to achieve heat resistance, the presence of aromatic and heterocyclic ring structures in the polymer main chain is necessary. Polybenzoxazines are a relatively new class of thermosetting resins possessing several unique properties, including high char yield, high glass transition temperature, low water absorption, low coefficient of thermal expansion and excellent thermal stability. Therefore, their uses have been the focus of several studies. ${ }^{1-9}$ Benzoxazine monomers are usually prepared through the Mannich reaction between a phenol $\left(\mathrm{R}_{2} \mathrm{C}_{6} \mathrm{H}_{4} \mathrm{OH}\right)$, an amine $\left(\mathrm{R}_{1} \mathrm{NH}_{2}\right)$ and formaldehyde. The choice of phenols and amines permits design flexibility of the benzoxazine monomers and tailoring of the resulting polybenzoxazine properties. It has been shown that the use of phenols and amines containing reactive functional groups significantly improves the thermal stability and char yield of the resulting polybenzoxazines. ${ }^{10-13}$

Several studies have been carried out on thermal degradation mechanisms and pyrolysis products of polybenzoxazines using TGA, TGA-Fourier transform infrared (TGA-FTIR) and/or gas chromatography-mass spectrometry (GC-MS) techniques. ${ }^{10-18}$ A significant role of the Mannich base in the thermal degradation of polybenzoxazines ${ }^{14}$ and the influence of phenolic structure on the initial rate of weight $\operatorname{loss}^{15}$ have been detected. The identification of thermal degradation products has significant importance not only in determining thermal characteristics but also to investigating polymerization and degradation mechanisms. For this purpose, model dimers, trimers and tetramers have been studied. ${ }^{16-18}$ However, in reality, both TGA-FTIR and GC-MS techniques suffer in identifying the primary thermal degradation products. Among the several techniques used to investigate thermal degradation products, only in the case of the direct pyrolysis mass spectrometry (DP-MS) technique are secondary and condensation reactions avoided. Hence, detection of highmass pyrolyzates and unstable thermal degradation products is possible. ${ }^{19-21}$ Thus, a better understanding of the thermal characteristics, polymerization, crosslinking and char formation processes can be achieved.

Recently, we applied the DP-MS technique to investigate not only the processes taking place during the curing of methylamineand phenol-based benzoxazines, but also to elucidate the thermal degradation mechanism. ${ }^{22}$ Besides the generally accepted ringopening polymerization of benzoxazines, attack of $\mathrm{NCH}_{2}$ groups

Correspondence to: Jale Hacaloglu, Department of Chemistry, Middle East Technical University, 06531 Ankara, Turkey. E-mail:jale@metu.edu.tr

† Present address: UNAM-Institute of Materials Science and Nanotechnology, Bilkent University, Ankara, 06800, Turkey.

a Department of Chemistry, Middle East Technical University, 06531 Ankara, Turkey

b Department of Macromolecular Science and Engineering, Case Western Reserve University, Cleveland, $\mathrm{OH} 44106$, USA 
to ortho and para positions of the phenol rings was elucidated. Also, strong evidences for a two-step polymerization mechanism starting via coupling of $\left(\mathrm{CH}_{3}\right) \mathrm{NCH}_{2}$ groups were detected. The dimer involving a diamine linkage, generated by coupling reactions, was polymerized either by attack of $\mathrm{NCH}_{2}$ groups or by vinyl polymerization.

In the study reported here, the DP-MS technique was applied to investigate thermal decomposition and crosslinking characteristics of polybenzoxazines prepared via curing model benzoxazine monomers. The monomers were synthesized from bisphenol- $A$ and methylamine (BA-m) or aniline (BA-a) and from phenol and aniline (Ph-a). The results for each sample were compared with those for phenol and methylamine (Ph-m) determined earlier. ${ }^{22}$ Detailed mechanisms for polymerization processes during curing are not given as the data available were not sufficient for this purpose. The proposed mechanisms involved only the polymer chains detected and/or should be present in order to explain the detection of certain degradation products.

\section{EXPERIMENTAL}

The benzoxazine monomers BA-m, BA-a and $\mathrm{Ph}$-a were synthesized and characterized as given in our previous study. ${ }^{1}$ The monomers were polymerized without any initiator by stepwise curing at $160^{\circ} \mathrm{C}(30 \mathrm{~min}), 180^{\circ} \mathrm{C}(30 \mathrm{~min}), 200^{\circ} \mathrm{C}(30 \mathrm{~min})$ and $210^{\circ} \mathrm{C}$ (120 min) in an oven.

TGA was performed with a TA Instruments TGA 2950 under nitrogen atmosphere at a flow rate of $90 \mathrm{~mL} \mathrm{~min}^{-1}$ and a heating rate of $10^{\circ} \mathrm{C} \mathrm{min}-1$. DP-MS analyses of samples $(0.010 \mathrm{mg})$ in quartz sample vials were performed using a Waters Micromass Quattro Micro GC mass spectrometer with a mass range of 10-1500 Da and an electron impact (EI) ion source, coupled to a direct insertion probe. El mass spectra $(70 \mathrm{eV})$, at a rate of $1 \mathrm{scan}$ per second, were recorded for both curing and pyrolysis processes. The stepwise curing programs used for the polymerization of the benzoxazines in the oven were also utilized in DP-MS analyses to investigate the curing processes. For analyses of the thermal behavior of polybenzoxazines, samples were heated to $650{ }^{\circ} \mathrm{C}$ at a rate of $10^{\circ} \mathrm{C} \mathrm{min}^{-1}$. The DP-MS analyses were repeated several times to ensure reproducibility.

\section{RESULTS AND DISCUSSION}

In order to investigate the polymerization processes of benzoxazines BA-m, BA-a and Ph-a, the curing program used for the preparation of the polybenzoxazines in an oven was applied inside the mass spectrometer. After the curing program was completed, the heating process was further continued to determine the thermal degradation characteristics of the polymer generated during the curing process.

\section{Curing of benzoxazine monomers}

The total ion current (TIC) curves (variation of total ion yield as a function of time and/or temperature) of $\mathrm{Ph}-\mathrm{a}, \mathrm{BA}-\mathrm{m}$ and $\mathrm{BA}-\mathrm{a}$ are shown in Fig. 1. The pyrolysis mass spectra recorded
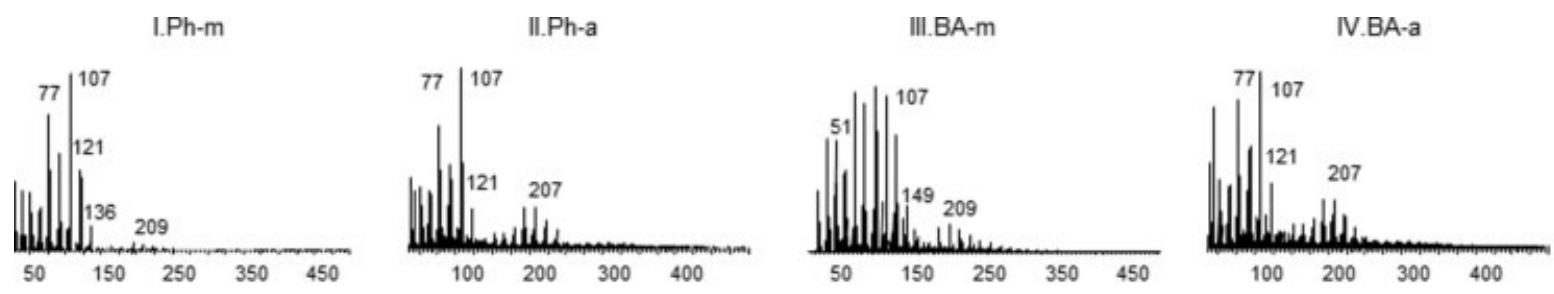

(d) $430-460^{\circ} \mathrm{C}$
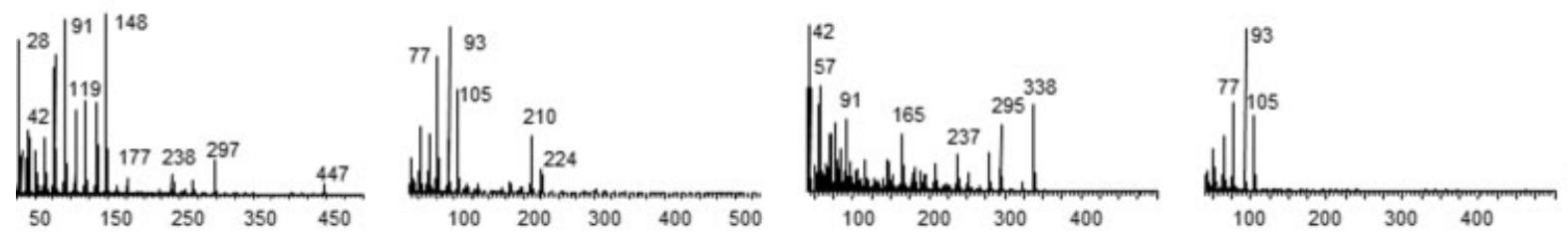

(c) $210^{\circ} \mathrm{C}$
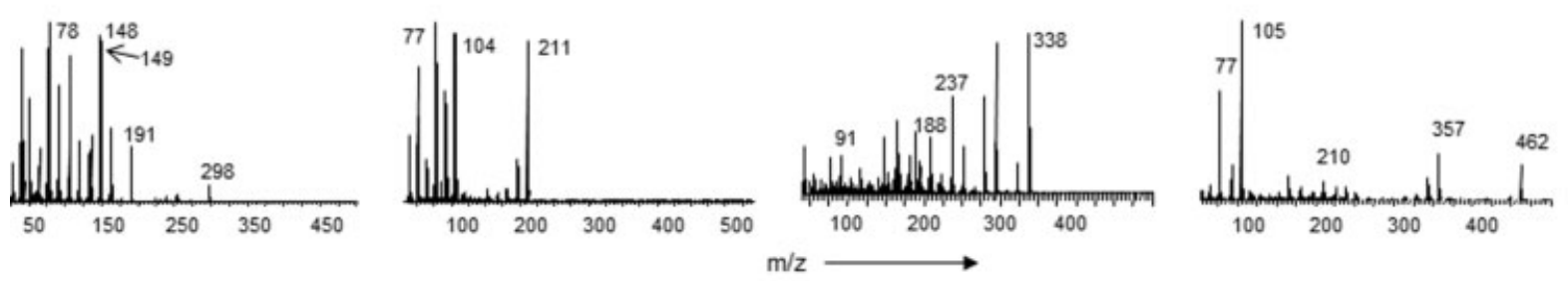

(b) $160^{\circ} \mathrm{C}$
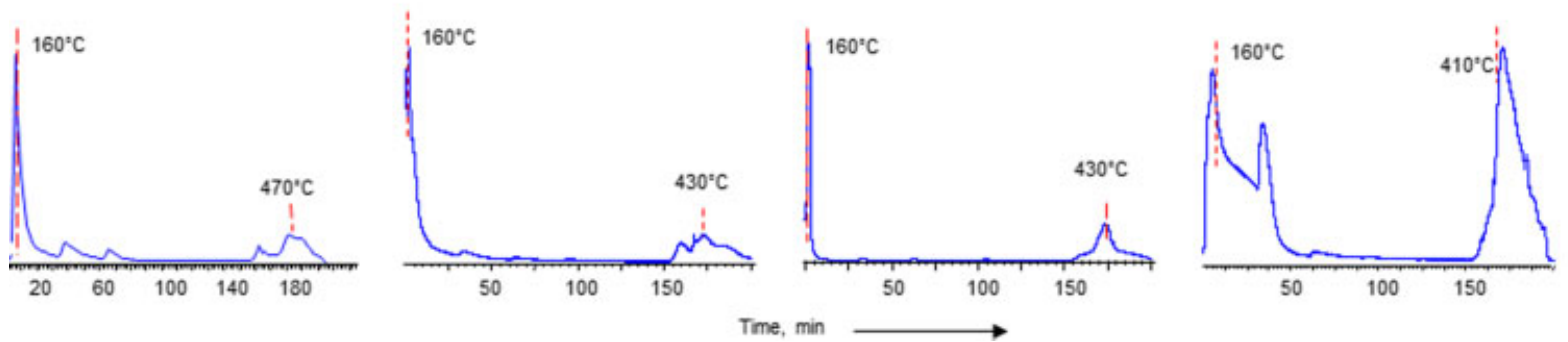

(a) Tic curve

Figure 1. (a) TIC curves and $(b-d)$ mass spectra at selected temperatures recorded during the curing and pyrolysis of Ph-m, Ph-a, BA-m and BA-a. 
at 160 and $210^{\circ} \mathrm{C}$ during curing and at above $400^{\circ} \mathrm{C}$ during the thermal degradation of the polymers generated inside the mass spectrometer are also shown in Fig. 1. The related data for $\mathrm{Ph}-\mathrm{m}$ are also included for comparison. Intense molecular ion peaks at 149, 211, 338 and 462 Da for Ph-m, Ph-a, BA-m and $B A-a$, respectively, are detected. The fragmentation patterns observed in the spectra recorded around $160^{\circ} \mathrm{C}$ are in accordance with dissociative ionization of aromatic ethers and secondary amines or anilines. Thus, evaporation of the monomers during the curing process under the high-vacuum conditions of the mass spectrometer is confirmed. For Ph-a, dimer peak at $422 \mathrm{Da}$, although significantly weak and undetectable in the given scale, is also detected, as was the case for Ph-m. ${ }^{22}$ Experiments were also carried out using recrystallized monomer in order to investigate the source of the dimer; either generated during transport and/or storage or during the curing process inside the mass spectrometer. The intensity of the diagnostic peaks of dimer diminished significantly in the mass spectra of the recrystallized benzoxazine monomer indicating that the dimer was mainly produced during storage and/or transport. The curing data for the recrystallized monomer and the monomer containing some dimer are almost identical, except for the presence of peaks related to evolution of dimer at initial stages of curing. Thus, the data obtained using the monomer sample involving some dimer are presented here, as its mass spectrum can be used as a reference for the purpose of investigation of thermal degradation products.

Inspection of single-ion evolution profiles indicates that, as the curing proceeds, the evolution of monomer decreases almost exponentially and totally disappears above $200^{\circ} \mathrm{C}$. However, in this region, low mass fragment peaks are still detected. Especially for aniline-based monomers, evolution of aniline is quite significant even in the final stage of curing. Thus, it can be concluded that the decomposition of the monomer, at least to a certain extent, occurs in the final stages of curing. After the curing process is completed, upon further heating, above $300^{\circ} \mathrm{C}$, peaks indicating the thermal degradation of the corresponding polybenzoxazines appear in the mass spectra. Thus, it can be concluded that polymerization of benzoxazines also occurs during the curing process even under the high-vacuum conditions of the mass spectrometer, although the evaporation of monomers has taken place.

\section{Thermal degradation of polybenzoxazines}

In general, if the polymerization takes place only by the mechanism given in the literature, as shown in Scheme 1, thermal degradation would most probably proceed by the cleavage of $\mathrm{CH}_{2}-\mathrm{N}-\mathrm{CH}_{2}$ linkages and a one-step thermal degradation mechanism would be expected. Then, the distribution of thermal degradation products of polybenzoxazines would resemble the fragmentation
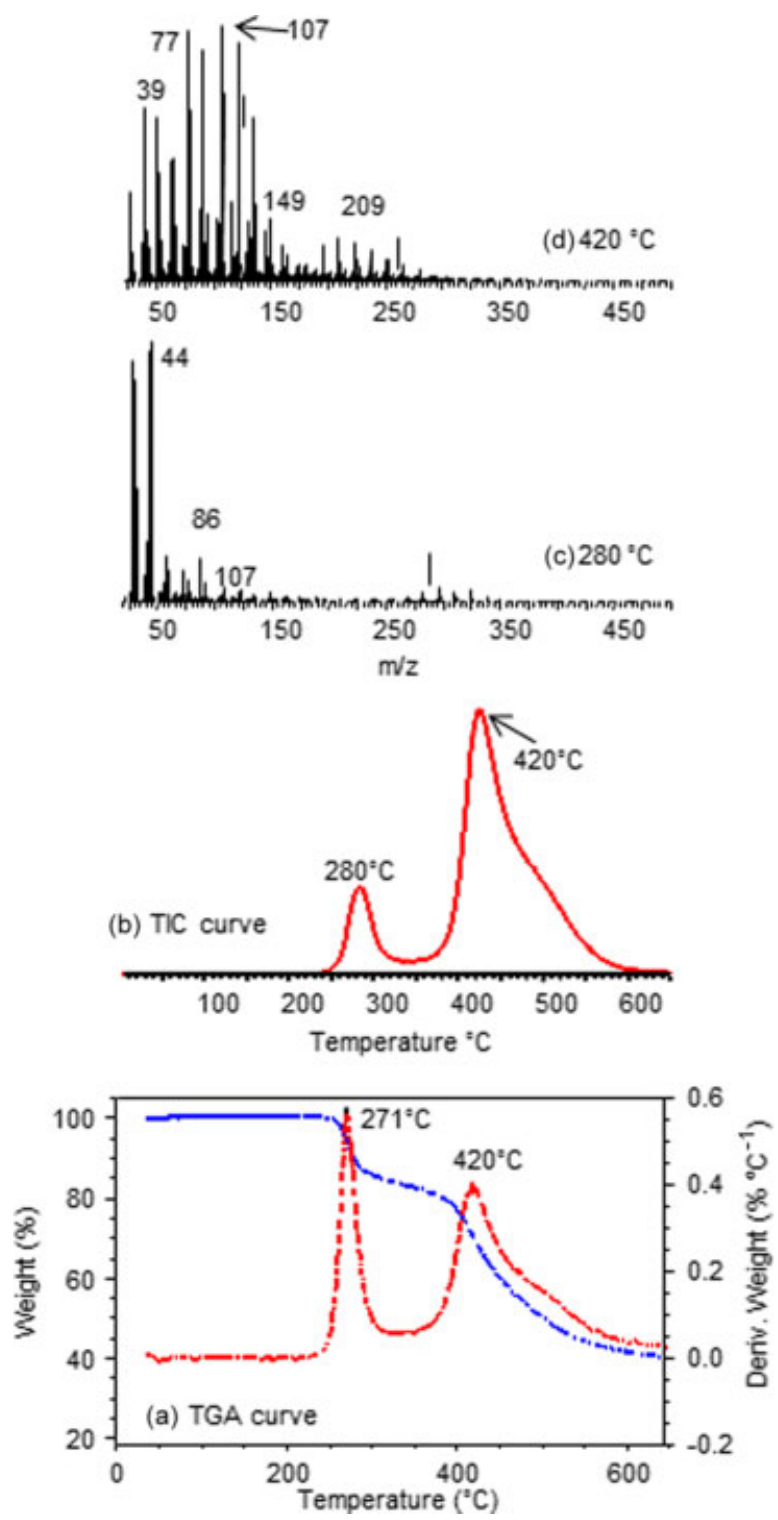

Figure 2. (a) TGA and (b) TIC curves and (c, d) mass spectra recorded during the pyrolysis of PBA-m.

patterns of the corresponding monomers and dimers. However, the pyrolysis mass spectra of all the polybenzoxazine samples are significantly different from the mass spectra of the corresponding monomers and dimers. Furthermore, single-ion evolution profiles of thermal degradation products show several peaks and shoulders

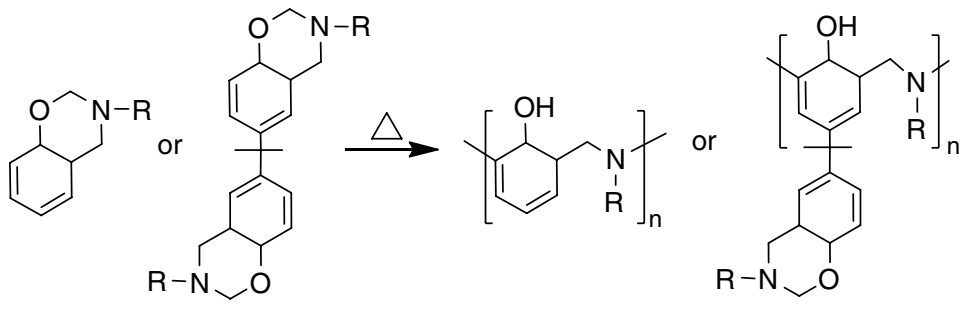

$$
\mathrm{R}=\mathrm{CH}_{3} \text { or } \mathrm{C}_{6} \mathrm{H}_{5}
$$

PPh-1m or $-1 a$

PBA-1m or $-1 \mathrm{a}$

Scheme 1. Expected ring-opening polymerization of benzoxazines. 


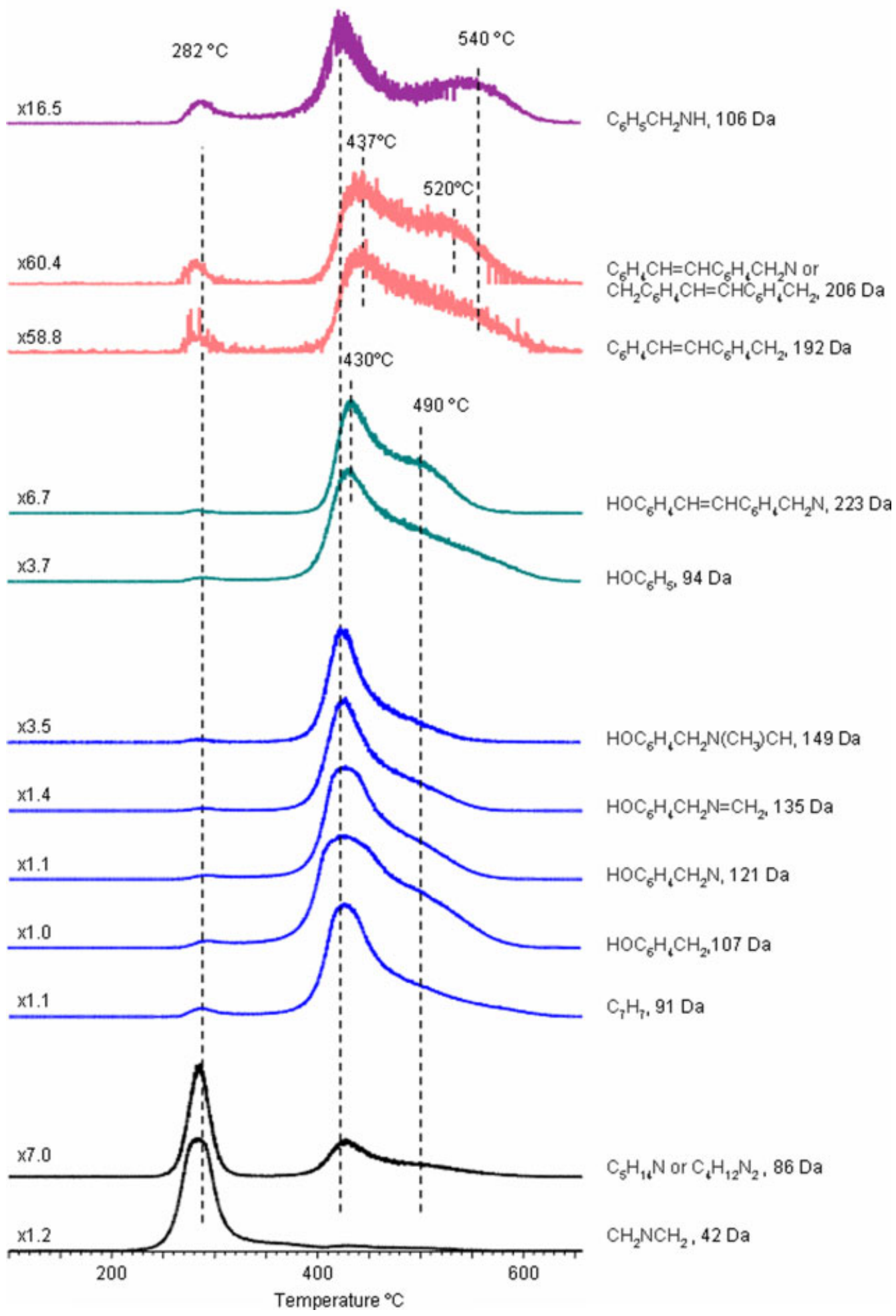

Figure 3. Evolution profiles of some diagnostic products detected during the pyrolysis of PBA-m.

indicating the presence of units with different stabilities and/or the occurrence of multi-step thermal decomposition. Therefore, polymerization of the monomers through opposing reaction pathways has to be considered as for polybenzoxazine based on phenol and methylamine (PPh-m). ${ }^{22}$
Polybenzoxazine based on bisphenol-A and methylamine (PBA-m)

The TGA curve of PBA-m shows two peaks, at 271 and $420^{\circ} \mathrm{C}$, the first being quite sharp, and a shoulder above $500^{\circ} \mathrm{C}$ (Fig. 2). The $\mathrm{TIC}$ curve recorded during the pyrolysis of PBA-m and the pyrolysis 


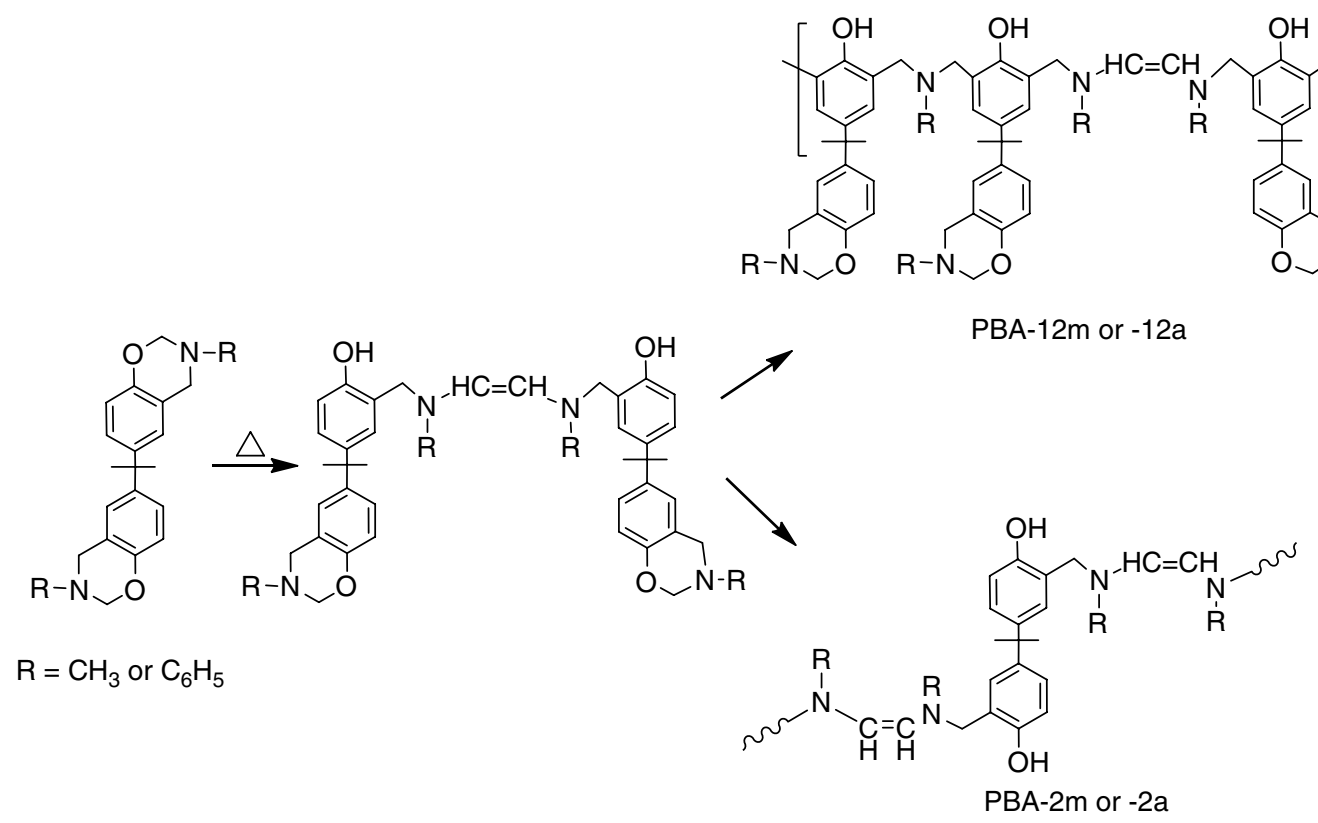

Scheme 2. Polymerization via generation of dimer by the coupling of $-\mathrm{NCH}_{2}$ groups.

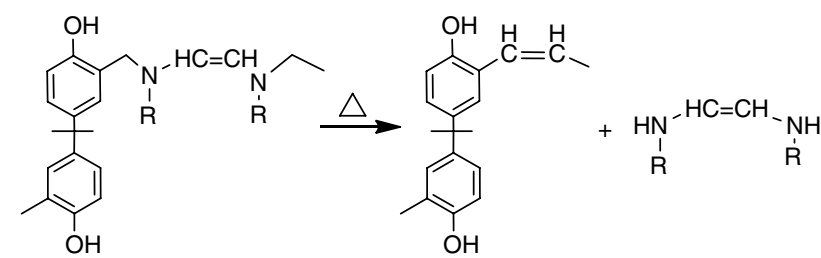

Scheme 3. Loss of diamine linkages and generation of a more stable structure that decomposes at elevated temperatures.

mass spectra recorded at the peak maxima are also shown in Fig. 2. The presence of more than one peak in the TGA and TIC curves points to either a multi-step thermal degradation process or the presence of more than one component with different thermal stabilities. The mass spectra recorded at the maxima and at the shoulder of the peaks are totally different. The evolution of alkylamines is detected at the initial stages of pyrolysis, at around $280^{\circ} \mathrm{C}$, while the fragments involving phenyl ring are detected at significantly higher temperatures, maximizing at around $425^{\circ} \mathrm{C}$. One of the most important findings is the evolution of fragments that can directly be attributed to alkylamines and/or diamines involving more than three carbon atoms. These products were also detected during the pyrolysis of PPh-m. ${ }^{22}$

Losses of alkylamines and diamines from PBA-m and PPh-m are detected at almost the same temperatures, at ca 280 and $282{ }^{\circ} \mathrm{C}$, respectively. ${ }^{22}$ However, the evolution of fragments involving aromatic units shifts about $50{ }^{\circ} \mathrm{C}$ to lower temperatures in the case of PBA-m compared to what is observed for phenol-based polybenzoxazine. This may be due to the presence of relatively weak $\mathrm{C}\left(\mathrm{CH}_{3}\right)_{2}$ linkages between the two phenol groups. Presence of very intense peaks due to fragments with only one phenyl ring pointed to the ready cleavage of these linkages, decreasing the thermal stability of the overall aromatic structure.

Diagnostic products of PBA-m, grouped according to the trends in their evolution profiles, are presented in Fig. 3. The products involving amines and/or diamines, as shown for $\mathrm{CH}_{2} \mathrm{NCH}_{2}$
(42 Da), $\mathrm{C}_{5} \mathrm{H}_{14} \mathrm{~N}$ or $\mathrm{C}_{4} \mathrm{H}_{12} \mathrm{~N}_{2}$ (86 Da), evolve mainly at around $280^{\circ} \mathrm{C}$. However, weak peaks with maxima at around 420 and $490^{\circ} \mathrm{C}$ are also present in their single-ion pyrograms. In this region phenyl-involving fragments such as $\mathrm{C}_{7} \mathrm{H}_{7}(91 \mathrm{Da})$, $\mathrm{HOC}_{6} \mathrm{H}_{4} \mathrm{CH}_{2}$ (107 Da), $\mathrm{HOC}_{6} \mathrm{H}_{4} \mathrm{CH}_{2} \mathrm{~N}(121 \mathrm{Da}), \mathrm{HOC}_{6} \mathrm{H}_{4} \mathrm{CH}_{2} \mathrm{~N}=\mathrm{CH}_{2}$ (135 Da) and $\mathrm{HOC}_{6} \mathrm{H}_{4} \mathrm{CH}_{2} \mathrm{~N}\left(\mathrm{CH}_{3}\right) \mathrm{CH}(149 \mathrm{Da})$ show an intense peak with a high-temperature shoulder at around $490^{\circ} \mathrm{C}$. Evolution of $\mathrm{HOC}_{6} \mathrm{H}_{5}$ (94 Da), $\mathrm{HOC}_{6} \mathrm{H}_{4} \mathrm{CH}=\mathrm{CHC}_{6} \mathrm{H}_{4} \mathrm{CH}_{2}$ (209 Da) and $\mathrm{HOC}_{6} \mathrm{H}_{4} \mathrm{CH}=\mathrm{CHC}_{6} \mathrm{H}_{4} \mathrm{CH}_{2} \mathrm{~N}(223 \mathrm{Da})$ is maximized at around $430{ }^{\circ} \mathrm{C}$. Yet, a broad shoulder at around $490^{\circ} \mathrm{C}$ is again present in their evolution profiles. Unsaturated products such as $\mathrm{C}_{6} \mathrm{H}_{4} \mathrm{CH}=\mathrm{CHC}_{6} \mathrm{H}_{4} \mathrm{CH}_{2}(192 \mathrm{Da})$ and $\mathrm{C}_{6} \mathrm{H}_{4} \mathrm{CH}=\mathrm{CHC}_{6} \mathrm{H}_{4} \mathrm{CH}_{2} \mathrm{~N}$ and/or $\mathrm{CH}_{2} \mathrm{C}_{6} \mathrm{H}_{4} \mathrm{CH}=\mathrm{CHC}_{6} \mathrm{H}_{4} \mathrm{CH}_{2}$ (206 Da) are detected at slightly higher temperatures. Their single-ion pyrograms show a maximum at around $437^{\circ} \mathrm{C}$ with a high-temperature tail. Loss of lowmass products such as $\mathrm{HOC}_{6} \mathrm{H}_{4} \mathrm{CH}$ and/or $\mathrm{C}_{6} \mathrm{H}_{5} \mathrm{CH}_{2} \mathrm{NH}$ (106 Da) is detected at even higher temperatures showing a maximum around $540{ }^{\circ} \mathrm{C}$.

Considering the similarities of the structures of phenol- and bisphenol-A-based benzoxazine monomers, similar polymerization reaction pathways can be proposed. The first possibility is of course the generally expected polymerization mechanism, the attack of $\mathrm{CH}_{3} \mathrm{NCH}_{2}$ groups generated upon ring opening of oxazine ring to ortho and para positions of the phenyl ring (PBA-1m) as shown in Scheme 1.

Another possible polymerization pathway involves two steps, the first being the coupling of $\mathrm{CH}_{3} \mathrm{NCH}_{2}$ groups yielding a dimer and the second being the polymerization of this dimer either by attack of $\left(\mathrm{CH}_{3}\right) \mathrm{NCH}_{2}$ groups to ortho and para positions or by vinyl polymerization. The evolution of intense diamine fragments with more than three carbon atoms which can be generated by the coupling of $\mathrm{NCH}_{2}$ groups during the pyrolysis supports the proposed mechanism shown in Scheme 2. For PBA$\mathrm{m}$, the relative yields of diamines are significantly higher than the corresponding ones for PPh-m; the intensity ratios of $\mathrm{OC}_{6} \mathrm{H}_{4} \mathrm{CH}_{2}$ and $\mathrm{C}_{4} \mathrm{~N}_{2} \mathrm{H}_{10}$ peaks are 7.0 and 58.4 for PBA-m and PPh-m, respectively, indicating a more than sevenfold increase. These 

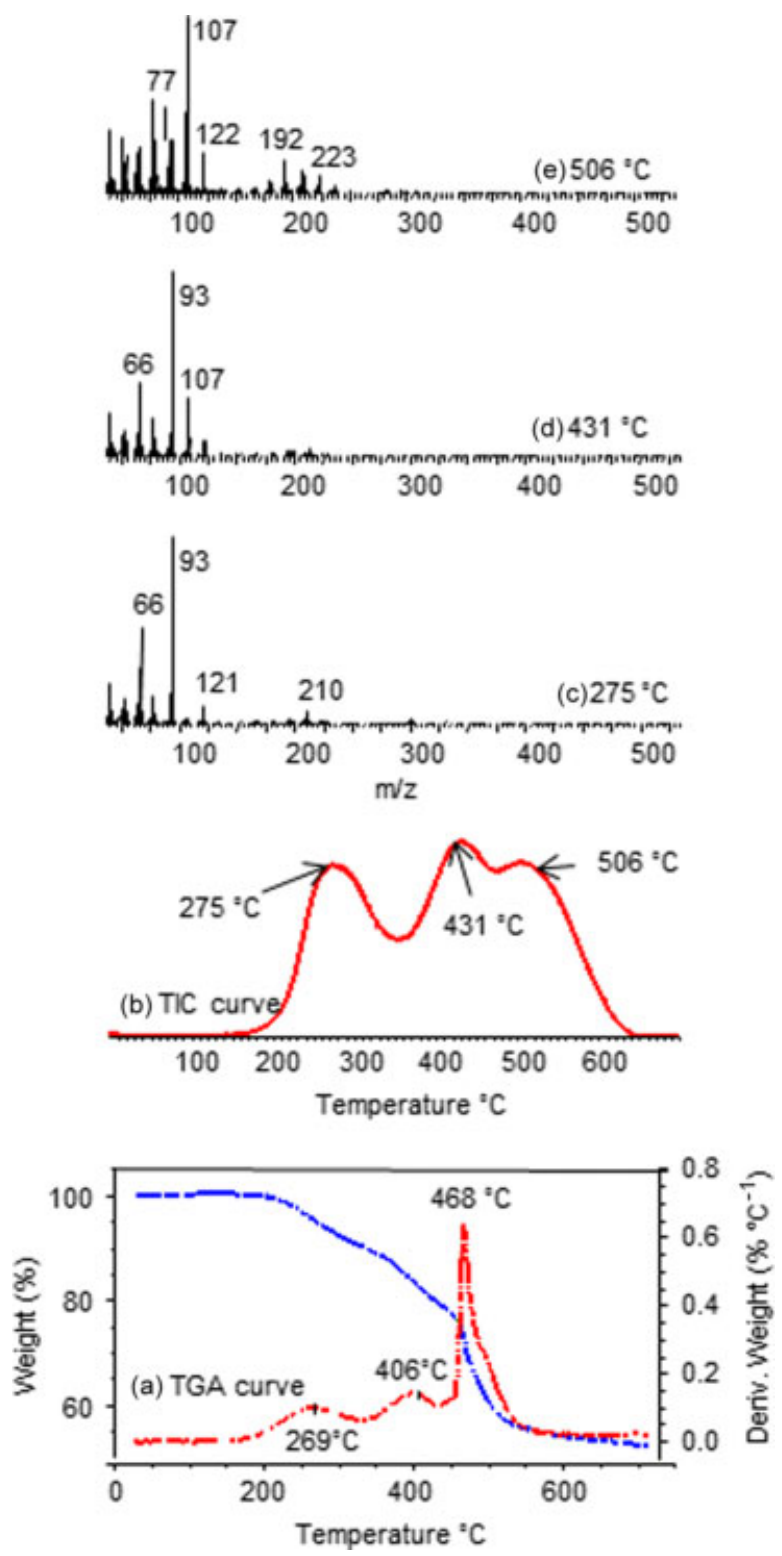

Figure 4. (a) TGA and (b) TIC curves and spectra recorded during the pyrolysis of PPh-a at (c) 275 (d) 431 and (e) $506^{\circ} \mathrm{C}$.

results pointed out that the coupling of $\mathrm{NCH}_{2}$ groups is more efficient for the benzoxazine based on bisphenol-A. It may be thought that for the bisphenol-A-based benzoxazine monomer, vinyl polymerization proposed for the phenol-based benzoxazine is not likely due to the presence of bulky groups. However, unlike phenol-based benzoxazines, the bisphenol-A-based benzoxazine may polymerize by coupling of $\mathrm{NCH}_{2}$ groups of both oxazine rings as shown in Scheme 2, yielding a more uniform structure (PBA$2 \mathrm{~m}$ ) along with the chains involving random diamine linkages (PBA-12m).

It may be thought that thermal decomposition starts by degradation of PBA-2m chains, loss of alkylamines and diamines around $280^{\circ} \mathrm{C}$. However, the significantly low yield of phenylinvolving fragments in this region reveals coupling of the radicals as shown in Scheme 3. The evolution of products maximizing at around $540{ }^{\circ} \mathrm{C}$ may then be attributed to decomposition of the polymeric backbone involving $-\mathrm{CH}=\mathrm{CH}$-linkages generated by the loss of diamines around $280^{\circ} \mathrm{C}$. Again, it may be concluded that vinyl polymerization and/or crosslinking of these units are not likely due to the presence of bulky groups.

On the other hand, the low-temperature evolutions of phenyl-involving fragments, $\mathrm{C}_{7} \mathrm{H}_{7}(91 \mathrm{Da}), \mathrm{C}_{6} \mathrm{H}_{5} \mathrm{OH}(94 \mathrm{Da})$, $\mathrm{C}_{6} \mathrm{H}_{5} \mathrm{CH}_{2} \mathrm{~N}(105 \mathrm{Da}), \mathrm{HOC}_{6} \mathrm{H}_{4} \mathrm{CH}_{2}(107 \mathrm{Da}), \mathrm{HOC}_{6} \mathrm{H}_{4} \mathrm{CH}_{2} \mathrm{~N}(121 \mathrm{Da})$, $\mathrm{HOC}_{6} \mathrm{H}_{4} \mathrm{CH}_{2} \mathrm{NCH}_{3} \quad(136 \mathrm{Da}), \mathrm{HOC}_{6} \mathrm{H}_{4} \mathrm{CH}_{2} \mathrm{~N}\left(\mathrm{CH}_{3}\right) \mathrm{CH}_{2} \quad(150 \mathrm{Da})$, $\mathrm{C}_{6} \mathrm{H}_{4} \mathrm{CH}=\mathrm{CHC}_{6} \mathrm{H}_{4} \mathrm{CH}_{2} \mathrm{~N}(206 \mathrm{Da})$ and $\mathrm{HOC}_{6} \mathrm{H}_{4} \mathrm{CH}=\mathrm{CHC}_{6} \mathrm{H}_{4} \mathrm{CH}_{2} \mathrm{~N}$ (223 Da), at around $420^{\circ} \mathrm{C}$, may be associated with the decomposition of PBA-1m and PBA-12m chains. Small shifts in the peak maxima and the evolution of these products also at around 490 and $520^{\circ} \mathrm{C}$ support the presence of linkages with different thermal stabilities along the polymer chains. Presence of random diamine linkages may be the probable cause of this behavior.

\section{Polybenzoxazine based on phenol and aniline (PPh-a)}

The TGA and TIC curves and the pyrolysis mass spectra at the peak maxima recorded during the pyrolysis of PPh-a are presented in Fig. 4. Three peaks with maxima at 275,430 and $520^{\circ} \mathrm{C}$ are present in the TIC curve as in the case of the TGA curve. The main decomposition product is aniline (93 Da) up to $450^{\circ} \mathrm{C}$. Above this temperature, the base peak is at $107 \mathrm{Da}$ which can readily be attributed to $\mathrm{HOC}_{6} \mathrm{H}_{4} \mathrm{CH}_{2}$ fragment.

Presence of chains with different structures and thermal stabilities is confirmed by the variations in the single-ion evolution profiles of fragments that cannot be differentiated from TGA and TIC curves. Single-ion pyrograms of some characteristic products are shown in Fig. 5. $\mathrm{C}_{6} \mathrm{H}_{5} \mathrm{NH}_{2}(93 \mathrm{Da}), \mathrm{HOC}_{6} \mathrm{H}_{4} \mathrm{CH}_{2} \mathrm{NHC}_{6} \mathrm{H}_{5}$ (199 Da) and $\mathrm{HOC}_{6} \mathrm{H}_{4} \mathrm{CH}_{2} \mathrm{NH}\left(\mathrm{C}_{6} \mathrm{H}_{5}\right) \mathrm{CH}_{2}$ (213 Da) show only two peaks in their evolution profiles, at 270 and $420^{\circ} \mathrm{C}$. Evolution of $\mathrm{HOC}_{6} \mathrm{H}_{5}(94 \mathrm{Da})$ is also detected in these regions; however, a high-temperature peak with a maximum at $532{ }^{\circ} \mathrm{C}$ is also present in its single-ion pyrogram. $\mathrm{HOC}_{6} \mathrm{H}_{3} \mathrm{CH}=\mathrm{CHC}_{6} \mathrm{H}_{4}$ and/or $\mathrm{C}_{6} \mathrm{H}_{4} \mathrm{NCH}_{2} \mathrm{C}_{6} \mathrm{H}_{4} \mathrm{~N}$ (194 Da) and $\mathrm{C}_{6} \mathrm{H}_{5} \mathrm{NHC}_{2} \mathrm{H}_{2} \mathrm{NHC}_{6} \mathrm{H}_{5}$ and/or $\mathrm{C}_{6} \mathrm{H}_{4} \mathrm{NHCH}_{2} \mathrm{C}_{6} \mathrm{H}_{4} \mathrm{NHCH}_{2}(210 \mathrm{Da})$ show again three peaks in their single-ion pyrograms. A shift by about $30^{\circ} \mathrm{C}$ to low temperatures for the second peak indicates the presence of chains with lower thermal stability. Fragments $\mathrm{C}_{7} \mathrm{H}_{7}(91 \mathrm{Da}), \mathrm{HOC}_{6} \mathrm{H}_{4} \mathrm{CH}_{2}$ and/or $\mathrm{C}_{6} \mathrm{H}_{5} \mathrm{NH}_{2} \mathrm{CH}_{2}$ (107 Da), $\mathrm{HOC}_{6} \mathrm{H}_{4} \mathrm{CH}_{2} \mathrm{NH}$ and/or $\mathrm{NH}_{2} \mathrm{CH}_{2} \mathrm{C}_{6} \mathrm{H}_{4} \mathrm{NH}_{2}$ $(122 \mathrm{Da})$ are evolved mainly above $450^{\circ} \mathrm{C}$, where their singleion pyrograms show two maxima at 460 and $508^{\circ} \mathrm{C}$. Evolution of $\mathrm{C}_{7} \mathrm{H}_{7}$ continues even at higher temperatures. Products that can be attributed to fragments involving unsaturation such as $\mathrm{C}_{6} \mathrm{H}_{4} \mathrm{CH}=\mathrm{NC}_{6} \mathrm{H}_{4} \mathrm{CH}$ and/or $\mathrm{C}_{6} \mathrm{H}_{4} \mathrm{CH}=\mathrm{CHC}_{6} \mathrm{H}_{4} \mathrm{CH}_{2}$ (192 Da), $\mathrm{C}_{6} \mathrm{H}_{4} \mathrm{CH}=\mathrm{CHC}_{6} \mathrm{H}_{4} \mathrm{CHNH}$ and/or $\mathrm{C}_{6} \mathrm{H}_{4} \mathrm{CH}_{2} \mathrm{NC}_{6} \mathrm{H}_{5} \mathrm{CH}=\mathrm{CH}$ (206), $\mathrm{HOC}_{6} \mathrm{H}_{4} \mathrm{CH}=\mathrm{CHC}_{6} \mathrm{H}_{4} \mathrm{CH}_{2} \mathrm{~N}$ and/or $\mathrm{HOC}_{6} \mathrm{H}_{4} \mathrm{CHN}\left(\mathrm{C}_{6} \mathrm{H}_{4} \mathrm{CH}=\mathrm{N}\right)$ (223 Da) and $\mathrm{C}_{6} \mathrm{H}_{4} \mathrm{CH}=\mathrm{CHC}_{6} \mathrm{H}_{4} \mathrm{CH}=\mathrm{CHC}_{6} \mathrm{H}_{4} \mathrm{CH}_{2}$ (294 Da) are evolved mainly at elevated temperatures and maximize at $532{ }^{\circ} \mathrm{C}$.

Units with different thermal stabilities may again be related to the presence of chains generated through the polymerization pathways proposed for PPh-m and PBA-m. However, as the para and ortho positions of the benzene ring in aniline are also potentially reactive, though to a lesser extent compared to the benzene ring of the phenols, another polymerization path may be the attack of $\mathrm{C}_{6} \mathrm{H}_{5} \mathrm{NCH}_{2}$ radicals to ortho and para positions of the aniline ring yielding a somewhat crosslinked structure (PPh-3a) as shown in Scheme 4. In a recent GC-MS study of thermal and thermo-oxidative degradation of aromatic aminebased polybenzoxazines, besides the major degradation product, aniline, generation of $p$-aminotoluene was detected supporting the above proposal. ${ }^{17}$ 


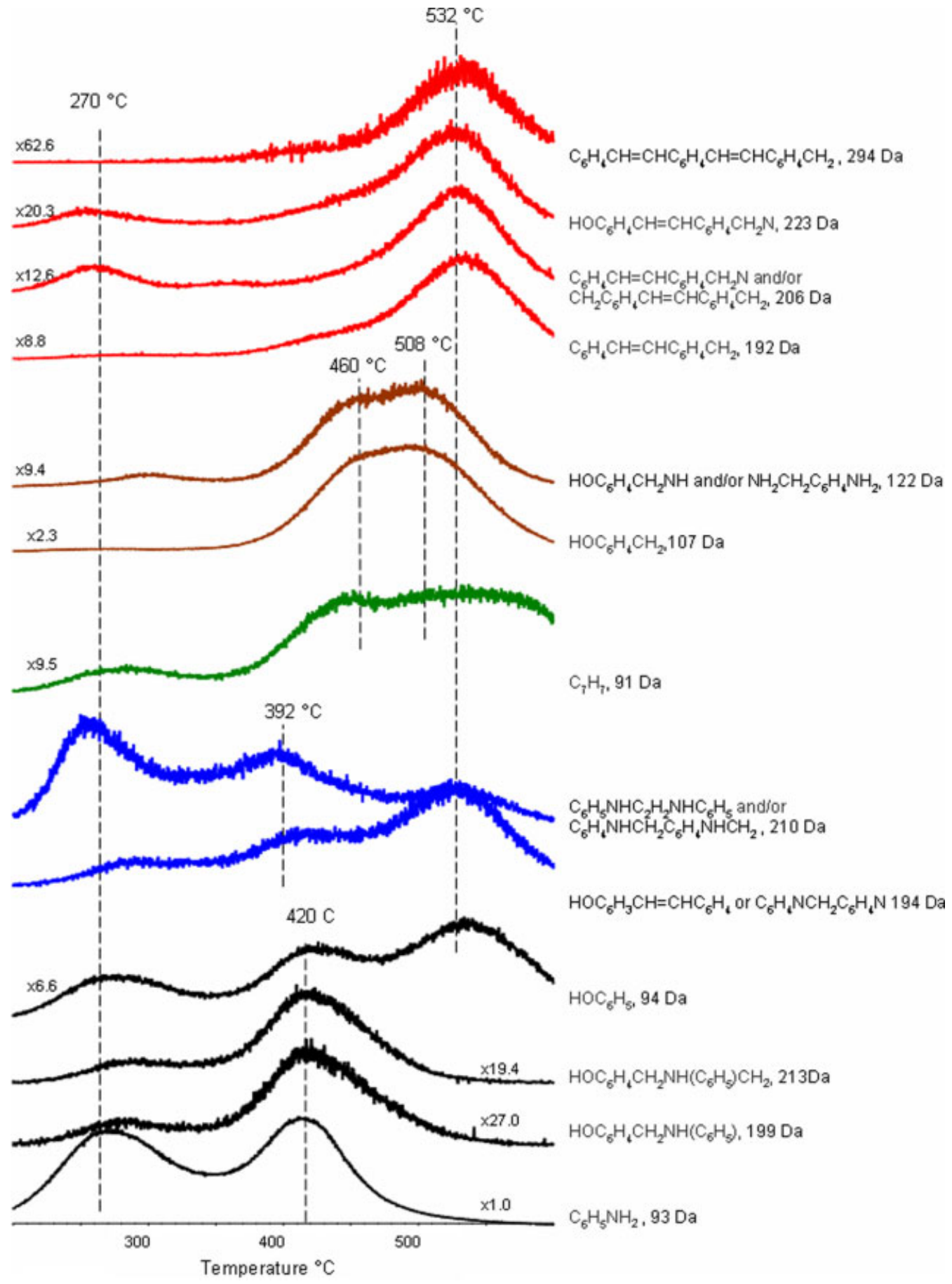

Figure 5. Evolution profiles of some diagnostic products detected during the pyrolysis of PPh-a.

The major thermal decomposition product aniline (93 Da) is detected in two distinct regions, at initial stages of pyrolysis at around $270^{\circ} \mathrm{C}$ and at around $420^{\circ} \mathrm{C}$. Taking into consideration all the possible polymeric structures, the low-temperature evolution of aniline at around $270^{\circ} \mathrm{C}$ can be attributed to decomposition units generated by the coupling of $\mathrm{C}_{6} \mathrm{H}_{5} \mathrm{NCH}_{2}$ groups of PPh-12a. It may be proposed that the radicals generated upon loss of aniline from PPh-12a at initial stages of pyrolysis and/or during curing couple to produce an unsaturated polymer backbone as in the case of PBA-12m and PBA-2m. The detection of fragments assigned to $\mathrm{C}_{6} \mathrm{H}_{4} \mathrm{CH}=\mathrm{CHC}_{6} \mathrm{H}_{4} \mathrm{CH}_{2}$ (192 Da),
$\mathrm{C}_{6} \mathrm{H}_{4} \mathrm{CH}=\mathrm{CHC}_{6} \mathrm{H}_{4} \mathrm{CH}_{2} \mathrm{~N}$ and/or $\mathrm{C}_{6} \mathrm{H}_{4} \mathrm{CHNC}_{6} \mathrm{H}_{4} \mathrm{CH}=\mathrm{CH}(206 \mathrm{Da})$, $\mathrm{HOC}_{6} \mathrm{H}_{4} \mathrm{CH}=\mathrm{CHC}_{6} \mathrm{H}_{4} \mathrm{CH}_{2} \mathrm{~N}$ and/or $\mathrm{HOC}_{6} \mathrm{H}_{4} \mathrm{CHN}\left(\mathrm{C}_{6} \mathrm{H}_{4} \mathrm{CH}=\mathrm{N}\right)$ (223 Da) and $\mathrm{C}_{6} \mathrm{H}_{4} \mathrm{CH}=\mathrm{CHC}_{6} \mathrm{H}_{4} \mathrm{CH}=\mathrm{CHC}_{6} \mathrm{H}_{4} \mathrm{CH}_{2} \quad$ (294 Da) at around $530{ }^{\circ} \mathrm{C}$ supports the above proposal.

The decomposition products reaching maximum yield at around $420{ }^{\circ} \mathrm{C}$ may be associated with the degradation of chains generated by ring-opening polymerization of oxazine ring and attack of $\mathrm{C}_{6} \mathrm{H}_{5} \mathrm{NCH}_{2}$ to ortho and para positions of the phenol rings (PPh-1a) as suggested previously. ${ }^{22}$ Thermal degradation of PPh-1a would occur by random cleavages at the $\beta$-carbon to phenol or nitrogen atom yielding fragments such as $\mathrm{HOC}_{6} \mathrm{H}_{4} \mathrm{CH}_{2} \mathrm{NHC}_{6} \mathrm{H}_{5}$ (199 Da), 


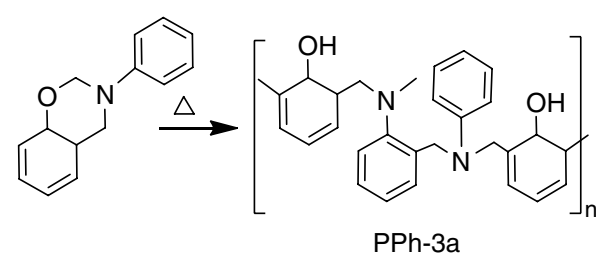

Scheme 4. Polymerization by the attack of $\mathrm{N}-\mathrm{CH}_{2}$ groups to aniline ring.

$\mathrm{HOC}_{6} \mathrm{H}_{4} \mathrm{CH}_{2} \mathrm{NH}\left(\mathrm{C}_{6} \mathrm{H}_{5}\right) \mathrm{CH}_{2}(213 \mathrm{Da})$ and $\mathrm{HOC}_{6} \mathrm{H}_{4} \mathrm{CHNC}_{6} \mathrm{H}_{4} \mathrm{CH}=\mathrm{N}$ and/or $\mathrm{CH}_{2} \mathrm{NC}_{6} \mathrm{H}_{4} \mathrm{CH}_{2} \mathrm{~N}\left(\mathrm{C}_{6} \mathrm{H}_{5}\right) \mathrm{CH}_{2}$ (223 Da) as in the case of the El dissociation of the monomer and dimer. The corresponding fragments $\mathrm{HOC}_{6} \mathrm{H}_{4} \mathrm{CH}_{2} \mathrm{NCH}_{3}(136 \mathrm{Da})$ and $\mathrm{HOC}_{6} \mathrm{H}_{4} \mathrm{CH}_{2} \mathrm{~N}\left(\mathrm{CH}_{3}\right) \mathrm{CH}_{2}$ $(150 \mathrm{Da})$ detected during the pyrolysis of PBA-m also reach a maximum yield at around $420^{\circ} \mathrm{C}$.

Evolution profiles of fragments $\mathrm{C}_{6} \mathrm{H}_{4} \mathrm{NCH}_{2} \mathrm{C}_{6} \mathrm{H}_{4} \mathrm{~N}$ (194 Da) and $\mathrm{C}_{6} \mathrm{H}_{5} \mathrm{NHC}_{2} \mathrm{H}_{2} \mathrm{NHC}_{6} \mathrm{H}_{5}$ and/or $\mathrm{C}_{6} \mathrm{H}_{4} \mathrm{NHCH}_{2} \mathrm{C}_{6} \mathrm{H}_{4} \mathrm{NHCH}_{2}$ (210 Da) at around $392{ }^{\circ} \mathrm{C}$ may be related to the decomposition of units generated by the attack of $\mathrm{C}_{6} \mathrm{H}_{5} \mathrm{NCH}_{2}$ groups to aniline rings indicating the presence of chains with lower thermal stability (PPh-3a). In addition, low-mass products such as $\mathrm{C}_{6} \mathrm{H}_{5} \mathrm{NH}_{2} \mathrm{CH}_{2}$ (107 Da) and $\mathrm{NH}_{2} \mathrm{CH}_{2} \mathrm{C}_{6} \mathrm{H}_{4} \mathrm{NH}_{2}$ (122 Da) may also be related to the decomposition of these units. The higher thermal stability may be attributed to the presence of some crosslinking. The two maxima in the evolution profiles of these products may be associated with the variations in the stability of these linkages as a result of polymerization through both phenyl and methylene groups and possibility of a crosslinked structure.

\section{Polybenzoxazine based on bisphenol-A and aniline (PBA-a)}

The TGA curve of PBA-a shows two overlapping peaks with maxima at 411 and $472{ }^{\circ} \mathrm{C}$ (Fig. 6). DP-MS results indicate a similar trend. The TIC curve and the pyrolysis mass spectra at the maximum $\left(406^{\circ} \mathrm{C}\right)$ and at the shoulder $\left(480^{\circ} \mathrm{C}\right)$ of the peak present in the TIC curve of PBA-a are shown in Fig. 6 . Again as in the case of $\mathrm{PPh}-\mathrm{a}$, the main decomposition product is aniline $(93 \mathrm{Da})$ and the peak at $107 \mathrm{Da}$ due to $\mathrm{HOC}_{6} \mathrm{H}_{4} \mathrm{CH}_{2}$ is the base peak above $450{ }^{\circ} \mathrm{C}$. The lack of low-temperature evolutions indicates a higher thermal stability for PBA-a compared to PPh-a. Also, evolution of the decomposition products is completed just above $500^{\circ} \mathrm{C}$. Thus, it may be concluded that PBA-a is a thermally more homogeneous polymer.

However, single-ion pyrograms of thermal degradation products again show different trends pointing to the presence of various polymeric structures. One thing that should be noticed is the disappearance of aniline evolution at low temperatures contrary to what is observed for PPh-a (Fig. 7). Actually, during the curing process of BA-a, aniline evolution is more significant compared to what is observed for PPh-a. Thus, it may be thought that this step has already been completed during the curing process and polymer chains involving $-\mathrm{CH}=\mathrm{CH}$-linkages are formed. Evolution of fragments such as $\mathrm{C}_{6} \mathrm{H}_{4} \mathrm{CH}=\mathrm{CHC}_{6} \mathrm{H}_{4} \mathrm{CH}_{2}$ (192 Da), $\mathrm{HOC}_{6} \mathrm{H}_{4} \mathrm{CH}=\mathrm{CHC}_{6} \mathrm{H}_{4} \mathrm{CH}_{2} \mathrm{~N}$ and/or $\mathrm{HOC}_{6} \mathrm{H}_{4} \mathrm{CHN}\left(\mathrm{C}_{6} \mathrm{H}_{4} \mathrm{CH}=\mathrm{N}\right)$ (223 Da) and $\mathrm{C}_{6} \mathrm{H}_{4} \mathrm{CH}=\mathrm{CHC}_{6} \mathrm{H}_{4} \mathrm{CH}=\mathrm{CHC}_{6} \mathrm{H}_{4} \mathrm{CH}_{2}$ (294 Da) is associated with the decomposition of polymer backbone involving unsaturated units. Their evolution profiles show two maxima at 435 and $500{ }^{\circ} \mathrm{C}$ as in the case of PBA-m. On the other hand, the corresponding phenol based benzoxazines PPh-a and PPh-m show a single peak at 532 and $548{ }^{\circ} \mathrm{C}$, respectively..$^{22}$ This behavior may be associated with the possibility of coupling of $\mathrm{N}-\mathrm{CH}_{2}$ groups of both oxazine rings in case of bisphenol-A-based benzoxazines
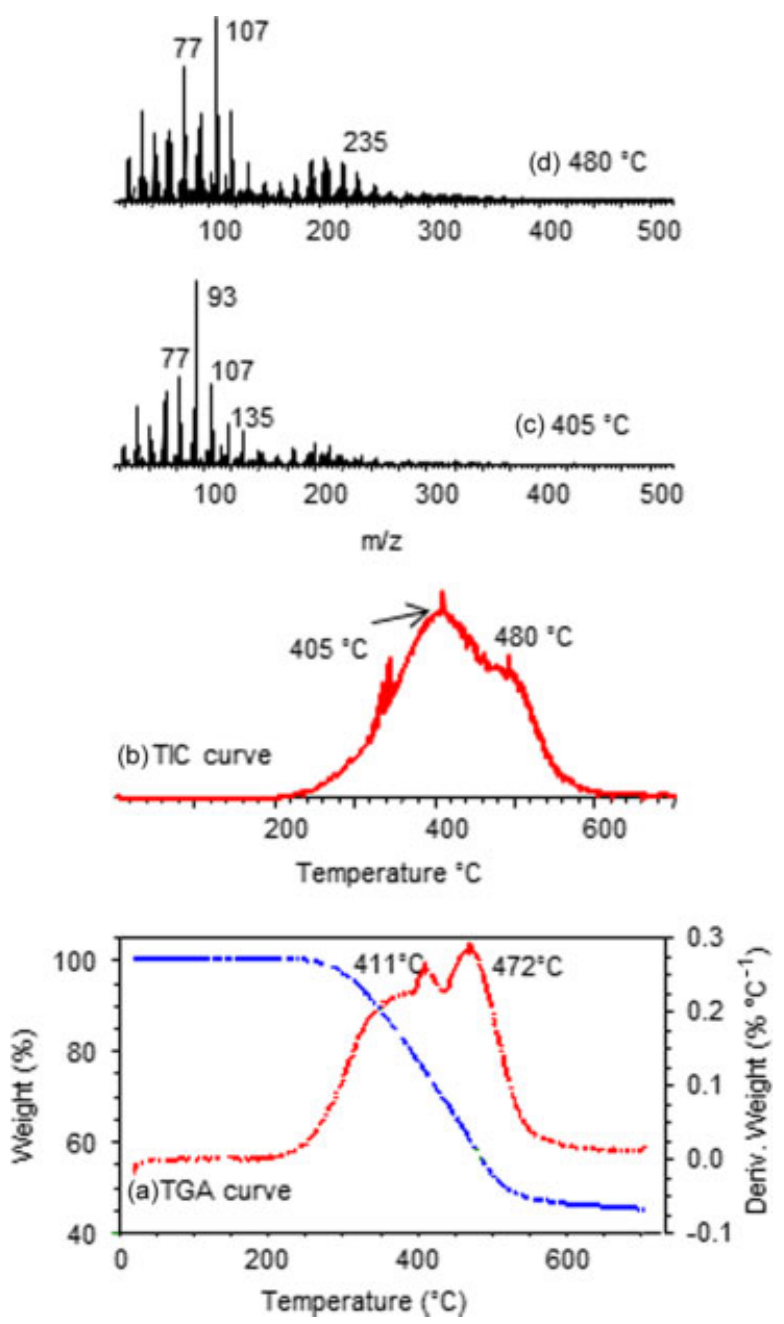

Figure 6. (a) TGA and (b) TIC curves and spectra recorded during the pyrolysis of PBA-a at (c) 405 and (d) $480{ }^{\circ} \mathrm{C}$.

yielding two different structures, PBA-12a and PBA-2a. For the corresponding phenol-substituted benzoxazines, as this coupling is unlikely, only PPh-12m and PPh-12a can be produced.

Fragments $\mathrm{HOC}_{6} \mathrm{H}_{4} \mathrm{CH}_{2} \mathrm{NHC}_{6} \mathrm{H}_{5}(199 \mathrm{Da})$ and $\mathrm{HOC}_{6} \mathrm{H}_{4} \mathrm{CH}_{2} \mathrm{NH}$ $\left(\mathrm{C}_{6} \mathrm{H}_{5}\right) \mathrm{CH}_{2}(213 \mathrm{Da})$ show only a single peak in their evolution profiles, with a maximum at $385^{\circ} \mathrm{C}$ (Fig. 7). These products may again be associated with the degradation of the chains generated via attack of $\mathrm{C}_{6} \mathrm{H}_{5} \mathrm{NCH}_{2}$ to ortho and para positions of the phenol rings (PBA-1a). The corresponding products for PPh-1a and PBA$1 \mathrm{~m}$ reach maximum yield at around $420^{\circ} \mathrm{C}$. Thus, a lower thermal stability for PBA-1a can be proposed.

Fragments $\mathrm{HOC}_{6} \mathrm{H}_{3} \mathrm{CH}=\mathrm{CHC}_{6} \mathrm{H}_{4}$ and/or $\mathrm{C}_{6} \mathrm{H}_{4} \mathrm{NCH}_{2} \mathrm{C}_{6} \mathrm{H}_{4} \mathrm{~N}$ (194 Da) and $\mathrm{C}_{6} \mathrm{H}_{5} \mathrm{NHC}_{2} \mathrm{H}_{2} \mathrm{NHC}_{6} \mathrm{H}_{5}$ and/or $\mathrm{C}_{6} \mathrm{H}_{4} \mathrm{NHCH}_{2} \mathrm{C}_{6} \mathrm{H}_{4}$ $\mathrm{NHCH}_{2}(210 \mathrm{Da})$ showing two peaks at 370 and $500^{\circ} \mathrm{C}$ may be related to the decomposition of units generated by the attack of $\mathrm{C}_{6} \mathrm{H}_{5} \mathrm{NCH}_{2}$ groups to aniline rings (PBA-3a; Scheme 4). The lower stability of these units compared to those generated by the attack of $\mathrm{C}_{6} \mathrm{H}_{5} \mathrm{NCH}_{2}$ groups to phenol rings is in accordance with the trends observed for PPh-3a. In addition the yield of these fragments significantly diminishes at high temperatures revealing a lower extent of crosslinking compared to what was detected for $\mathrm{PPh}-3 \mathrm{a}$. The first peak in the evolution profiles of products such as $\mathrm{C}_{6} \mathrm{H}_{5} \mathrm{OH}(94 \mathrm{Da})$ and $\mathrm{C}_{7} \mathrm{H}_{7}(91 \mathrm{Da})$ is maximized at 390 and $410{ }^{\circ} \mathrm{C}$, 


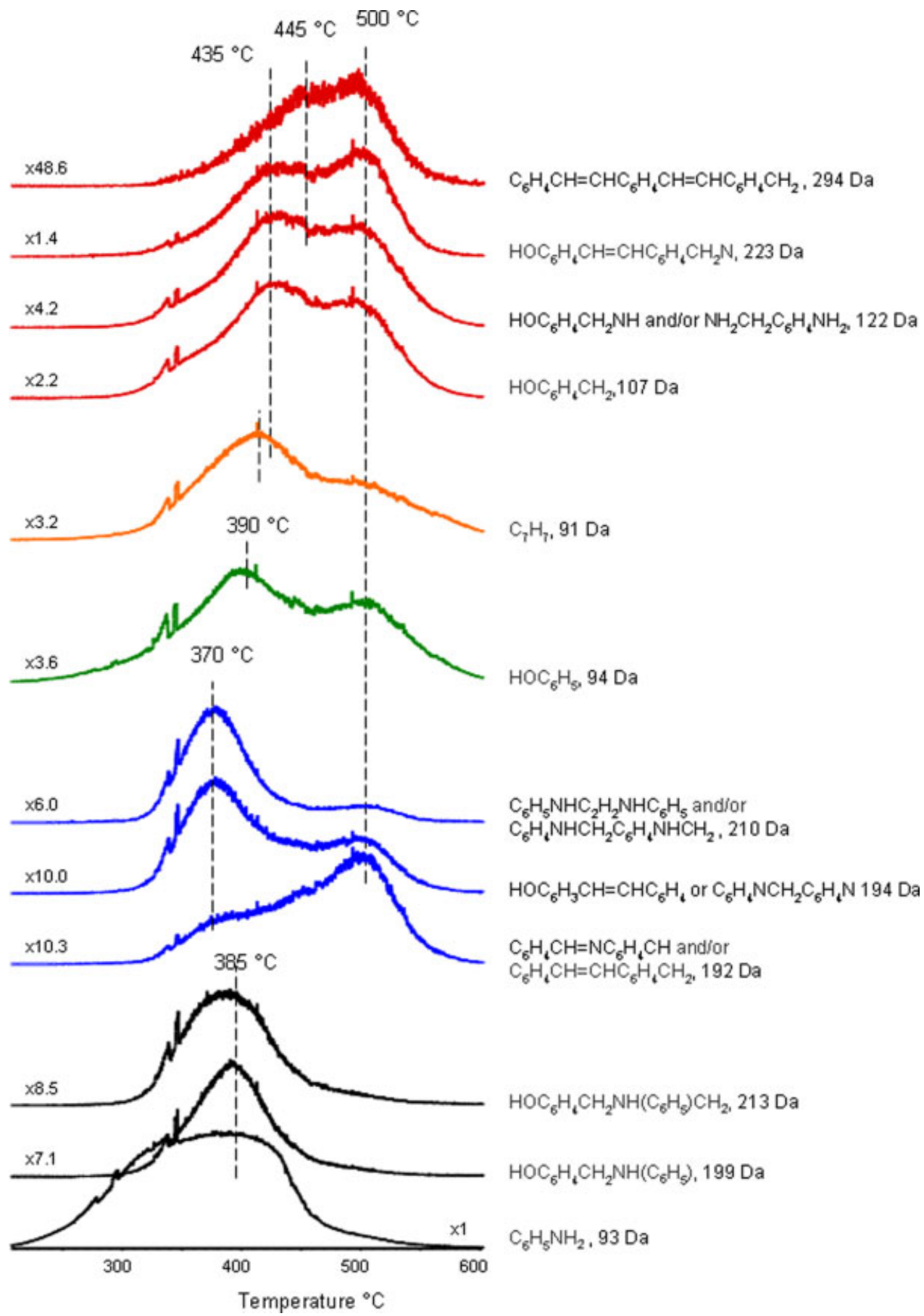

Figure 7. Evolution profiles of some diagnostic products detected during the pyrolysis of PBA-a.

respectively, indicating again a lower thermal stability. The hightemperature peak in their single-ion pyrograms is also maximized at $500^{\circ} \mathrm{C}$, in the region where unsaturated units are decomposed, as in the case of PPh-a.

\section{CONCLUSIONS}

DP-MS analyses pointed to a multi-step thermal degradation for all the polybenzoxazines under investigation. In general, thermal decomposition of phenol-based benzoxazines was completed at higher temperatures compared to bisphenol-A-based benzox- azines. For all polybenzoxazines, thermal degradation started by the loss of alkylamines and diamines in the case of PBA-m and PPh$\mathrm{m}$ and by evolution of aniline in the case of PPA-a due to cleavage of units generated by coupling of $\mathrm{CH}_{3} \mathrm{NH}_{2}$ and/or $\left(\mathrm{C}_{6} \mathrm{H}_{5}\right) \mathrm{NCH}_{2}$ groups. Unsaturated units involving $-\mathrm{CH}=\mathrm{CH}$-groups generated upon loss of nitrogen-containing fragments decomposed at relatively high temperatures. The peak maxima increased in the order PBA-a $<$ PBA-m $<$ PPh-a $<$ PPh-m. Evolution profiles of these products showed two overlapping peaks for bisphenolA-based polybenzoxazines indicating the presence of different units due to coupling of $\mathrm{NCH}_{2}$ groups of one or both oxazine 
rings. Thermal stability of the chains generated by the attack of $\mathrm{NCH}_{2}$ groups to ortho and para positions of phenol ring increased almost in the same order. For aniline-based polybenzoxazines, PPh-a and PBA-a, decomposition of chains generated by attack of $\mathrm{NCH}_{2}$ groups to ortho and para positions of aniline ring was detected at relatively low temperatures pointing to lower stability compared to the ones generated by the attack of $\mathrm{NCH}_{2}$ groups to ortho and para positions of phenol ring. Evolution of fragments involving unsaturation, at elevated temperatures for PPh-m, was not observed for PBA-m, PPh-a and PBA-a. These products were associated with the degradation of unsaturated, most probably crosslinked, polymer backbone generated by the loss of phenolic side-chains of the polymer produced by vinyl polymerization of the dimer involving diamine units. Thus, it may be concluded that vinyl polymerization of the units generated by coupling of $\mathrm{NCH}_{2}$ groups was not likely when bulky groups were bonded to nitrogen atoms.

\section{ACKNOWLEDGEMENTS}

This work was partially supported by TUBITAK Research Funds TBAG-106T092 and TBAG-109T028.

\section{REFERENCES}

1 Ning X and Ishida H, J Polym Sci Polym Chem Ed 32:1121-1129 (1994).

2 Nair CPR, Prog Polym Sci 29:401-498 (2004).

3 Ghosh NN, Kiskan B and Yagci Y, Prog Polym Sci 43:5084-5096 (2007).
4 Takeichi T, Kawauchi T and Agag T, Polym J 40:1121-1131 (2008).

5 Yagci Y, Kiskan B and Ghosh NN, J Polym Sci A: Polym Chem 47:5565-5576 (2009).

6 Liu YF, Zhang J, Liu Z, Li ZH and Yue ZQ, J Appl Polym Sci 124:813-822 (2012).

7 Wang YH, Chang CM and Liu YL, Polymer 53:106-112 (2011).

8 Kiskan B, Ghosh NN and Yagci Y, Polym Int 60:167-177 (2011).

9 Chen KC, Li HT, Huang SC, Chen WB, Sun KW and Chang FC, Polym Int 60:1089-1096 (2011).

10 Low HY and Ishida H, J Polym Sci B: Polym Phys 37:647-659 (1999).

11 Brunovska Z and Ishida H, J Appl Polym Sci 73:2937-2949 (1999).

12 Brunovskaa Z, Lyona $\mathrm{R}$ and Ishida $\mathrm{H}$, Thermochim Acta 357-358:195-203 (2000).

13 Kim HJ, Brunovska Z and Ishida H, Polymer 40:6565-6573 (1999).

14 Low HY and Ishida H, J Polym Sci B: Polym Phys 36:1935-1946 (1998).

15 Low HY and Ishida H, Polymer 40:4365-4376 (1999).

16 Hemvichian K, Kim HD and Ishida H, Polym Degrad Stab 87:213-224 (2005).

17 Hemvichian K and Ishida H, Polymer 43:4391-4402 (2002).

18 Hemvichian K, Laobuthee A, Chirachanchai S and Ishida H, Polym Degrad Stab 76:1-15 (2002).

19 Fares MM, Yalcin T, Hacaloglu J, Gungor A and Suzer S, Analyst 119:693-696 (1994).

20 Uyar T, Tonelli AE and Hacaloglu J, Polym Degrad Stab 91:2960-2967 (2006).

21 Uyar T, Koyuncu Z, Ishida H and Hacaloglu J, Polym Degrad Stab 93:2096-2113 (2008).

22 Bagherifam S, Uyar T, Ishida H and Hacaloglu J, Polym Test 29:520-526 (2010). 